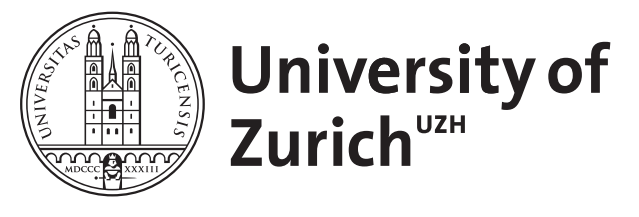

\title{
Pulmonary hypertension: Classification and pathobiology
}

Huber, Lars C ; Vrugt, Bart ; Arrigo, Mattia

\begin{abstract}
Pulmonary hypertension is defined as an increase of the mean pulmonary arterial pressure above $25 \mathrm{~mm} \mathrm{Hg}$ and, as such, the diagnosis requires invasive haemodynamic measurement by right heart catheterisation. More than just a single disease, pulmonary hypertension is an umbrella term that includes many different disorders and pathophysiological entities. However, most forms of pulmonary hypertension share a final common pathway, in particular the trias of vasoconstriction, microthrombosis and vascular remodelling. The classification of pulmonary hypertension has been subjected to many changes within the last decade. At the same time, major achievements in our understanding of the complex pathobiology have been made. Here, these developments are discussed in the light of the recently published report from the fifth World Symposium on pulmonary hypertension.
\end{abstract}

Posted at the Zurich Open Repository and Archive, University of Zurich

ZORA URL: https://doi.org/10.5167/uzh-103457

Journal Article

Published Version

Originally published at:

Huber, Lars C; Vrugt, Bart; Arrigo, Mattia (2014). Pulmonary hypertension: Classification and pathobiology. Cardiovascular Medicine, 17(11):312-319. 


\title{
Pulmonary hypertension: Classification and pathobiology
}

\author{
An article from the series "Pulmonary hypertension" \\ Lars C. Huber, Bart Vrugt, Mattia Arrigo \\ Division of Pulmonology (LH), Institute for Surgical Pathology (BV) and Division of Cardiology (MA), University Hospital, Zurich, \\ Switzerland
}

\begin{abstract}
Summary
Pulmonary hypertension is defined as an increase of the mean pulmonary arterial pressure above $25 \mathrm{~mm} \mathrm{Hg}$ and, as such, the diagnosis requires invasive haemodynamic measurement by right heart catheterisation. More than just a single disease, pulmonary hypertension is an umbrella term that includes many different disorders and pathophysiological entities. However, most forms of pulmonary hypertension share a final common pathway, in particular the trias of vasoconstriction, microthrombosis and vascular remodelling. The classification of pulmonary hypertension has been subjected to many changes within the last decade. At the same time, major achievements in our understanding of the complex pathobiology have been made. Here, these developments are discussed in the light of the recently published report from the fifth World Symposium on pulmonary hypertension.
\end{abstract}

\section{Definition and haemodynamics}

Pulmonary arterial pressure (PAP) is a function of cardiac output, left atrial pressure and pulmonary vascular resistance. The pulmonary circulation is a low-pressure system and the mean pulmonary arterial pressure (mPAP) does not exceed $20 \mathrm{~mm} \mathrm{Hg}$ in healthy individuals [1]. Pulmonary hypertension is defined as an increase of the mPAP above $25 \mathrm{~mm} \mathrm{Hg}$. Pressure values ranging from 21 to $24 \mathrm{~mm} \mathrm{Hg}$ have been associated with a high risk to develop overt pulmonary hypertension in a subgroup of patients, for example those with connective tissue disease [2], but otherwise these patients are not well defined and not much data exist on the prognostic and therapeutic consequences. Use of

Funding / potential competing interests: Lars Huber is supported by the Swiss National Science Foundation (SNF Grant 31003A_144212" the role of microRNAs in pulmonary hypertension: diagnosis and treatment") the term "borderline pulmonary hypertension" is thus not recommended [3]. Increasing age [4] and body weight [5] have been associated with a rise of systolic pulmonary arterial pressure (sPAP) and might explain the gap between normal mPAP and pulmonary hypertension.
The presence of pulmonary hypertension might be determined by echocardiography, which, depending on the underlying cause of elevated pulmonary pressure, provides an excellent screening tool. However, sensitivity and specificity of this method is limited [6]. Diagnosis is thus confirmed by invasive haemodynamic assessment with right heart catheterisation at rest. An inadequate elevation of pulmonary pressure upon exercise has been part of former definitions of pulmonary hypertension but, due to lack of standardisation, is no longer a criterion.

The differentiation of pulmonary hypertension due to left heart disease from the other forms is crucial. As suggested by guidelines, the pulmonary arterial wedge pressure (PAWP, also known as "wedge pressure") is used to estimate left atrial pressure in clinical practice. In healthy subjects, PAWP reflects left atrial pressure, which is extensively determined by left ventricular end-diastolic pressure (LVEDP). Several conditions interfere with this assumption and may lead to misclassification of pulmonary hypertension. Since pulmonary vessels are not stiff pipes but rather compressible tubes, an increase of the alveolar pressure (e.g., by pulmonary disease, mechanical ventilation with positive end-expiratory pressure) may compress the pulmonary capillary bed. This phenomenon, known as the Starling resistor model [7], explains the observation of elevated PAWP without underlying left-heart disease (left-atrial pressure and LVEDP are normal) in the context of pulmonary diseases. Conversely, PAWP was found to be only a moderate discriminator in patients with normal or high LVEDP in one recent study [8]. When left heart

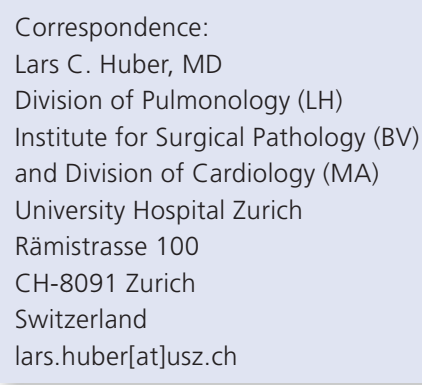


disease is strongly suspected in the evaluation of pulmonary hypertension, concomitant measurement of LVEPD might be indicated. However, routine assessment of pulmonary hypertension relies on measurement of PAWP.

PAWP values $\leq 15 \mathrm{~mm} \mathrm{Hg}$ define precapillary pulmonary hypertension. PAWP values $>15 \mathrm{~mm} \mathrm{Hg}$ suggest elevations of the pulmonary pressure by hydrostatic back pressure due to left-sided cardiac disorders, a condition which is coined postcapillary pulmonary hypertension. When the PAWP exceeds $15 \mathrm{~mm} \mathrm{Hg}$, the difference between diastolic pulmonary arterial pressure (dPAP) and the PAWP further defines the presence of isolated postcapillary (dPAP-PAWP $<7 \mathrm{~mm} \mathrm{Hg}$ ) or combined pre- and postcapillary pulmonary hypertension (dPAP-PAWP $\geq 7 \mathrm{~mm} \mathrm{Hg}$ ). The use of passive, reactive and "out-of-proportion" pulmonary hypertension has been abandoned in the context of left heart disease [9].

Other haemodynamic parameters (table 1) such as cardiac output, pulmonary vascular resistance and transpulmonary pressure gradient are not required for diagnosis but help to identify the pathophysiological entities that result in elevated pulmonary pressure. Cardiac output is the mathematical product of heart rate and stroke volume (and, when further divided by body surface area, is referred to as cardiac index).

Pulmonary vascular resistance is calculated by input pressure (i.e., mPAP) minus output pressure (i.e., PAWP, divided by cardiac output ( $1 / \mathrm{min})$ and is quantified by Wood units $(\mathrm{mm} \mathrm{Hg} \times \mathrm{min} / \mathrm{l})$. Pulmonary vascular resistance is about $1 / 10$ of the systemic vascular resistance. Wood units $>3$ indicate pulmonary hypertension, and, conversely, patients with values $<3$ are unlikely to have pulmonary hypertension. Pulmonary vascular resistance is not a part of the general definition of pulmonary hypertension and is not needed for the workup of all patients with pulmonary hypertension.

Vasoreactivity testing is mandatory only in the diagnostic workup of patients with idiopathic pulmonary arterial hypertension but is not recommended in all other forms of the disease [3]. Responders to vasoreagi-
Figure 1

Haemodynamic assessment. Swan-Ganz catheter [63] in situ. For details see text.

$\mathrm{mPAP}=$ mean pulmonary arterial pressure; PAWP = pulmonary arterial wedge pressure; LVEDP = left ventricular enddiastolic pressure.

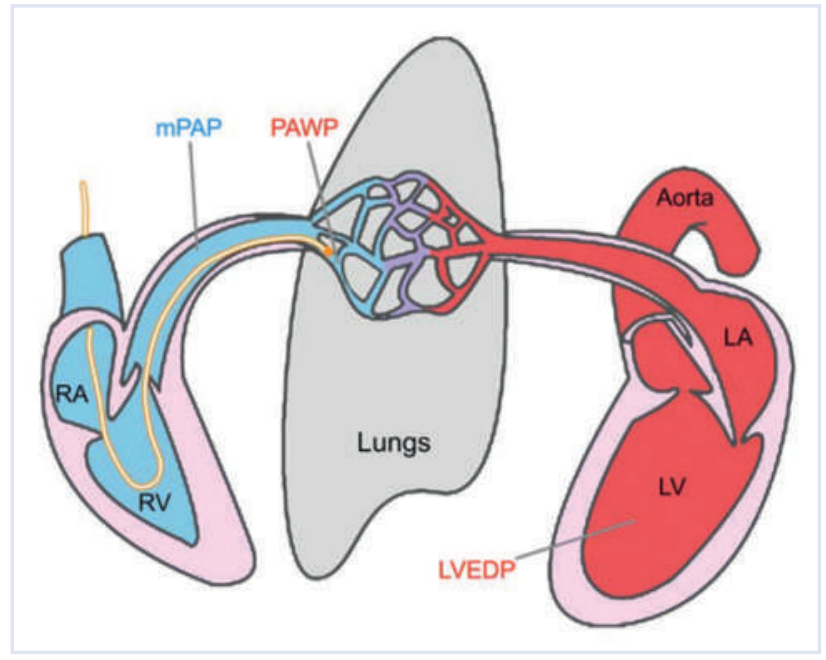

bility testing (e.g. NO inhalation) are defined by a decrease of the mPAP of more than $10 \mathrm{~mm} \mathrm{Hg}$ to an absolute value $<40 \mathrm{~mm} \mathrm{Hg}$ without concomitant reduction of the cardiac output. Vasoresponders probably reflect an early state of the disease in which vasoconstriction predominantes. These patients are treated with calcium channel blockers as first line treatment but require close follow-up since only half of them show longterm responses [10].

Recent studies suggest that occult left heart failure is common in patient with pulmonary hypertension [11] and misclassification of these patients might result in use of "PH-target"-therapies without evidence of benefit. The application of a fluid bolus (e.g., 250 or $500 \mathrm{ml}$ saline) during right heart catheterisation to identify these patients is not defined and routine application of this test cannot be recommended at the moment.

Figure 1 shows the different pressure levels assessed by right heart catheterisation. A modified "diagnostic algorithm" is provided in figure $2[3,12]$. For clin-

\section{Table 1}

Common haemodynamic parameters.

\begin{tabular}{|c|c|c|c|}
\hline Abbreviation & Definition & Calculation & Reference value \\
\hline $\mathrm{CO}$ & Cardiac output & & $4-8 \mathrm{l} / \mathrm{min}$ \\
\hline $\mathrm{Cl}$ & Cardiac index & & $2.5-4.2 \mathrm{l} / \mathrm{min} / \mathrm{m}^{2}$ \\
\hline mPAP & Mean pulmonary artery pressure & & 9-20 mm Hg \\
\hline dPAP & Diastolic pulmonary artery pressure & & \\
\hline PAWP & Pulmonary artery wedge pressure & & $\leq 15 \mathrm{~mm} \mathrm{Hg}$ \\
\hline LVEDP & Left ventricular end-diastolic pressure & & $\leq 15 \mathrm{~mm} \mathrm{Hg}[12,68]$ \\
\hline TPG & Transpulmonary gradient & mPAP - PAWP & $\leq 12 \mathrm{~mm} \mathrm{Hg}$ \\
\hline DPD & Diastolic pressure difference & dPAP - PAWP & $\leq 7 \mathrm{~mm} \mathrm{Hg}$ \\
\hline \multirow[t]{2}{*}{ PVR } & Pulmonary vascular resistance & TPG/CO & $<2$ WU (Wood units) \\
\hline & & $80 \times \mathrm{TPG} / \mathrm{CO}$ & $<160$ dyn $\times \mathrm{sec} / \mathrm{cm}^{5}$ \\
\hline
\end{tabular}


ical practice in cardiology, it is important to distinguish pulmonary hypertension due to left heart disease, the most common form that causes elevated pulmonary pressure, from other forms of pulmonary hypertension.

\section{Classification and epidemiology}

Pulmonary hypertension is a big umbrella term that summarises several diseases and entities that all result in elevation of the pulmonary pressure. According

\section{Figure 2}

Diagnostic approach to pulmonary hypertension. History and clinical signs might suggest the presence of pulmonary hypertension. Step 1: Normal levels of NT-proBNP and absence of right heart hypertrophy in ECG have been described to have a high sensitivity to exclude pulmonary hypertension [64]. Echocardiography (TTE) is used as screening tool. mPAP might be estimated by adding the right ventricular to right atrial mean systolic gradient to right atrial pressure [65] or from the estimated systolic pulmonary pressure (right ventricular to right atrial maximal systolic gradient + right atrial pressure): $\mathrm{mPAP}=\mathrm{sPAP} \times 0.61+2 \mathrm{~mm} \mathrm{Hg}$ [66] When pulmonary hypertension is suggested by these screening tools, underlying heart disease (step 2) and chronic lung disorders (step 3) have to be excluded (RX = chest radiography; $\mathrm{PFT}=$ pulmonary function testing incl. diffusion capacity for carbon monoxide); BGA = blood gas analysis; $\mathrm{HRCT}$ = high-resolution computed tomography). In the absence of such conditions, chronic thromboembolic pulmonary hypertension is investigated by ventilation/perfusion scintigraphic or MR angiography [67] (step 4). Diagnosis of pulmonary hypertension is confirmed by right heart catheterisation and can further be classified in pre- and postcapillary elevation of pulmonary pressure. According to the levels of the diastolic pressure difference (DPD), postcapillary pulmonary hypertension is isolated or combined with precapillary pressure elevation (step 5).

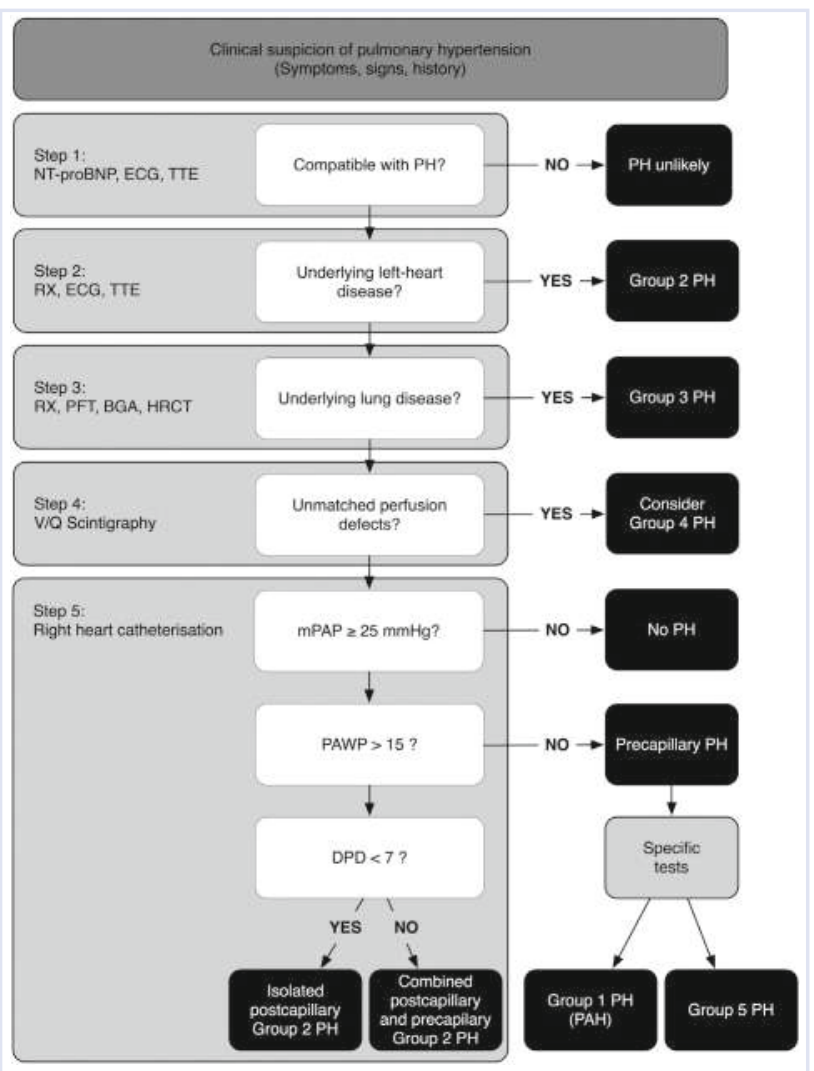

Table 2

Classification of pulmonary hypertension (simplified).

1. Pulmonary arterial hypertension
1.1 Idiopathic PAH
1.2 Heritable PAH
1.3 Drug- and toxin-induced
1.4 Associated with connective tissue disease, HIV infection,
portal hypertension, congenital heart diseases,
schistosomiasis
2. Pulmonary hypertension due to left heart disease
3. Pulmonary hypertension due to lung diseases and/or hypoxia
4. Chronic thromboembolic pulmonary hypertension (CTEPH)
5. Pulmonary hypertension with unclear multifactorial
mechanisms

to a classification system used since 1998, pulmonary hypertension can be classified into five entirely different clinical and pathophysiological groups (table 2). Group 1, which is the main focus of this article, includes idiopathic and hereditary pulmonary arterial hypertension, pulmonary hypertension associated with different risk factors and predisposing conditions, pulmonary veno-occlusive disease, pulmonary capillary haemangiomatosis, persistent pulmonary hypertension of the newborn and congenital heart disease. Only group 1 is termed pulmonary arterial hypertension, while all the other groups are named pulmonary hypertension. Much confusion is encountered in clinical practice with this nomenclature. Group 2 summarises pulmonary hypertension due to pathologies of the left heart [13, 14], while the pressure elevation in group 3 is caused by diseases of the lung. These two groups include the most prevalent aetiologies for pulmonary hypertension, although exact epidemiological data do not exist. Group 4 represents pressure elevation due to chronic thromboembolic events. Other miscellaneous conditions resulting in pulmonary hypertension, such as metabolic, haematologic and systemic disorders, are subsumed in group 5. The definitions of primary and secondary pulmonary hypertension are no longer used. With a prevalence of 5-15 cases per million [15], pulmonary arterial hypertension is considered to be an orphan disease. Pulmonary hypertension, however, is a very common condition.

The most common causes for group 1 pulmonary hypertension include idiopathic and hereditary pulmonary arterial hypertension, pulmonary arterial hypertension in the context of connective tissue disease, congenital heart disease, portopulmonary hypertension in liver disease, drug-induced pulmonary hypertension, and HIV infection (fig. 3) [16]. Exact epidemiological data on the incidence of these forms is lacking and vary between different registries. The most common forms are shortly discussed here, for more details please refer to [17]. 


\section{Figure 3}

Epidemiology of pulmonary hypertension. Schematic representation of the 5 pulmonary hypertension groups (grey circles). The most prevalent aetiologies of pulmonary hypertension are group 2 (left heart diseases, PH-LHD) and group 3 (lung diseases, PH-LUNG). Group 1 (pulmonary arterial hypertension, $\mathrm{PAH}$ ) is an orphan disease with different causes (prevalence according to [16]). The prevalence of chronic thromboembolic pulmonary hypertension (CETPH) and of pulmonary hypertension due to miscellaneous aetiologies (PH-misc) is unknown.

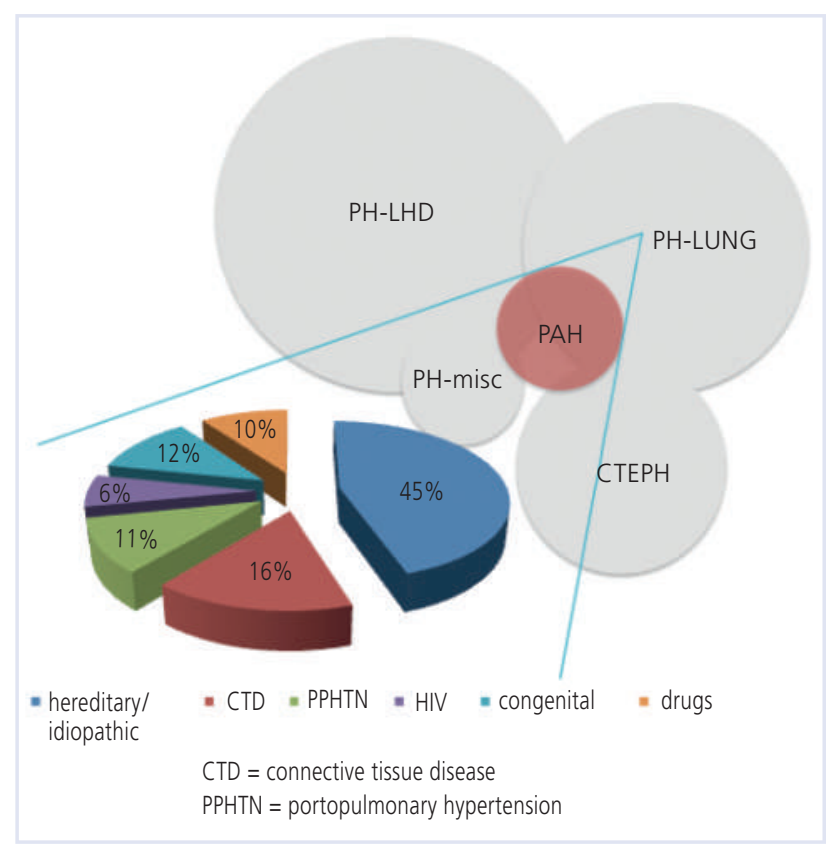

\section{Hereditary pulmonary arterial hypertension}

The most common mutations in pulmonary arterial hypertension are loss-of-function mutations in the gene encoding for the bone morphogenetic protein receptor type II (BMPR2, see below), which is located on the long arm of chromosome 2 (2q33). Since the initial report on BMPR2 mutation [18] more than 300 other genetic variants have been identified in the context of pulmonary hypertension. These mutations can be found in about $70 \%$ of familial and in up to $30 \%$ of idiopathic forms of pulmonary arterial hypertension. These forms are thus summarised as hereditary pulmonary arterial hypertension. While several other mutations of downstream factors of BMPR2, coreceptors and other mediators have been described, changes in the expression of BMPR2 remain the ones with the most importance for prevalence and pathogenesis. Screening for such mutations is not recommended routinely and, in our centre, is rarely performed.

\section{Connective tissue disease}

Pulmonary hypertension is a comorbidity that can be found in all connective tissue diseases, including systemic sclerosis, systemic lupus erythematosus, polymyositis/dermatomyositis (antisynthetase syndrome) [19] and rheumatoid arthritis. Epidemiological studies suggest that pulmonary hypertension is a common finding in patients with systemic sclerosis (more than $10 \%$ of patients [20]). However, pulmonary hypertension in systemic sclerosis is complicated by the fact that elevation of pulmonary pressure can also be caused - or at least be aggravated - by parenchymal lung disease and left heart failure making it very difficult to identify the causative factor that results in elevated pulmonary pressure [21]. Additional vasodilatation of the pulmonary circulation may aggravate left heart failure and explain why patients with pulmonary hypertension associated with systemic sclerosis have a worse outcome when treated with PH-target therapies compared to those with pulmonary arterial hypertension due to other aetiologies [22]. Patients with connective tissue disease should be screened with annual echocardiography or when developing symptoms.

\section{Congenital heart disease / GUCH (grown-up congenital heart disease)}

The prevalence of pulmonary arterial hypertension in adults with congenital heart defects (CHD) is not well defined. It is strongly influenced by the type of defect, and type and timing of surgical repair. Chronic exposure of the pulmonary vascular bed to volume overload secondary to chronic high output and in particular to pressure overload (e.g. through ventricular or arterial shunts), may result in obstructive arteriopathy of pulmonary vessels. The extreme form of pulmonary arterial hypertension associated with CHD is Eisenmenger's syndrome, where PVR equalises or exceeds systemic vascular resistance resulting in cyanosis and clubbing through bidirectional or reversal shunting [23]. In industrialised countries congenital heart defects are usually diagnosed early in life and timely surgical repair prevents development of pulmonary arterial hypertension in most cases. As a result, the cohort of Eisenmenger patients is slowly decreasing in these countries. In developing countries Eisenmenger's syndrome is still prevalent.

With modern heart surgery and cardiology care most patients with congenital heart disease now survive to adulthood, even those with complex lesions [24]. These adults are not cured. Some of these complex patients (i.e., Fontan circulation for single-ventricle physiology) may develop pulmonary vascular disease in long-term follow-up with adverse outcome [25]. Other types of pulmonary hypertension observed in the context of CHD (e.g., congenital cardiomyopathies, inflow / outflow obstructions) belong to group 2 .

\section{Portopulmonary hypertension}

Pulmonary arterial hypertension is present in $5-10 \%$ of patients with cirrhotic liver disease [26]. The exact pathogenetic mechanisms underlying elevation of pulmonary pressure are not completely clear. Incomplete clearance of vasoconstrictive mediators by the diseased 
liver and increase in inflammatory cytokines such as Interleukin-6 [27] might play a major role. Of interest, onset and prevalence of pulmonary hypertension is not related to the severity of liver disease and can be observed at any stage of the Child-Pugh classification. Portopulmonary hypertension is more common in female patients and in autoimmune hepatitis, whereas male gender and hepatitis $\mathrm{C}$ infection appear to be protective factors [28]. The therapy of co-existing liver and pulmonary hypertensive disease is a challenge particularly because betablockers applied to reduce portal pressure and prevent variceal bleeding should not be used in pulmonary hypertension. In addition oral anticoagulation is contraindicated in liver disease because of the risk of coagulopathies. Finally, $\mathrm{PH}$ target therapies might be hepatotoxic and orthotopic liver transplantation is difficult to perform in the presence of pulmonary hypertension.

\section{Drugs and toxins}

Several drugs and toxins have been investigated for an association with the development of pulmonary arterial hypertension. A causative role has been proposed for several anorexigens including a recent report on Benfluorex in France [29], and selective serotonine reuptake inhibitors in pregnant women that result in pulmonary arterial hypertension of the newborns. Illicit drugs such as cocaine and amphethamine-like drugs show a possible association. The tyrosine kinase inhibitor dasatinib has recently been associated with pulmonary hypertension [30] and, following initial enthusiasm in case reports [31,32] the use of tyrosine kinase inhibitors for pulmonary hypertension is now questioned [33]. An association is less likely for oral contraceptives and oestrogens. The role of smoking is controversial but prevalence of smoking appears to be higher in patients with pulmonary arterial hypertension [34]. In addition, smoking is associated with increased vascular remodelling in pulmonary arteries [35] and significant reduction of diffusion capacity [36].

\section{Human immunodeficiency virus}

HIV patients have an increased prevalence for pulmonary arterial hypertension [37]. Current epidemiological data suggest that about $0.5 \%$ of HIV patients develop elevated pulmonary arterial pressure. The pathogenesis of HIV-associated pulmonary hypertension is unclear, but chronic inflammation is thought to be of importance. The interesting data on the causative role of human herpesvirus-8 [38] (which is responsible for the development of Kaposi Sarcoma and lymphoproliferative Castleman's disease) have not been confirmed. Whether antiretroviral treatment might also reduce pulmonary arterial pressure remains controversial but it has been shown that prolonged treatment of subjects with HIV-related pulmonary hypertension results in normalisation of elevated pulmonary pressure in about one third of patients and is associated with reduced mortality [39].

\section{Pathobiology}

In the update from Nice 2013 on the clinical classification of pulmonary hypertension almost 30 entities are listed as different aetiologies for pulmonary hypertension. Of interest, most of these forms result in the small pulmonary arteries $(<300 \mu \mathrm{m})$ in a final common pathway of vasoconstriction, microthrombosis and vascular remodelling (fig. 4). This makes it impossible to distinguish different aetiologies in established disease by, for example, pathomorphology of pulmonary vessels.

\section{Vasoconstriction}

Vasoconstriction without microthrombosis and vascular remodelling possibly reflects an early and probably reversible stage of disease. Contraction of vascular smooth muscle cells, mainly mediated by excessive release of intracellular calcium [40], is due to a dysbalance of vasoactive factors. For example, elevated levels of endothelin-1, one of the strongest vasoconstrictors, detected in the circulation of patients with pulmonary arterial hypertension, correlate positively with haemodynamic parameters such as mPAP [41]. Conversely, the production of the vasorelaxative factor nitric oxide and its second messenger cyclic guanosine monophosphate (cGMP) are reduced in patients with pulmonary arterial hypertension [42]. Similarly, relaxative prostacyclins and cyclic adenosine monophosphate are reduced in vessels of patients with pulmonary arterial hypertension [43]. Most currently used PH-target therapies are specific vasodilators that interact with one of these systems. In addition, cardiopulmonary reflexes might trigger or - by a vicious cycle of hypoxia and vasoconstriction - aggravate the constriction of pulmonary arteries. The most important reflex in this context

\section{Figure 4}

Pathogenetic factors in pulmonary hypertension. Most aetiologies identified in pulmonary hypertension result in a final common pathway with vasoconstriction, microthrombosis and vascular remodelling.

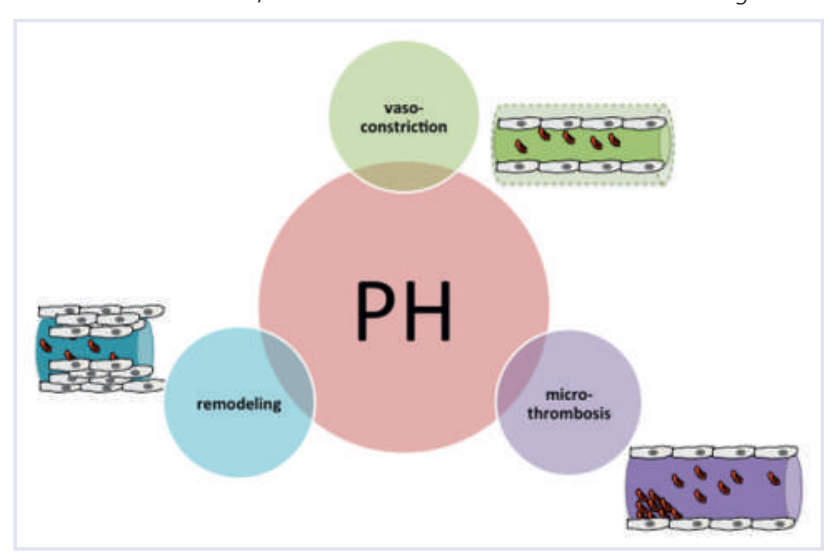


is the Euler-Liljestrand reflex, which describes a paradoxical response of pulmonary artery smooth muscle cells to hypoxia and which minimises ventilation/perfusion mismatch in the lung by directing blood flow to ventilated areas. The Hermo-Weiler (or Kitaev)-reflex is important for the development of pulmonary hypertension in left heart disease and describes vasoconstriction of precapillary pulmonary arteries upon pressure increase of the left atrium (reviewed in [44]).

\section{Microthrombosis}

It is well known that in situ thrombotic events within small pulmonary arteries are common in patients with pulmonary arterial hypertension and occur more frequently with longer duration of the disease and increasing age of the patient. Several abnormalities in the coagulation system have been described including reduced anticoagulatory activity of protein $\mathrm{C}$ and $\mathrm{S}$, increased activity of von Willebrand factor and reduced fibrinolysis by increased expression of the plasminogen activator inhibitor [45-47]. The increased coagulability with thrombosis contributes to the pathobiologic evolution of the disease and justifies the use of oral anticoagulation in patients with pulmonary arterial hypertension [48].

\section{Figure 5}

Remodelling. Various vascular abnormalities in a patient with idiopathic pulmonary arterial hypertension.

A Pulmonary artery with media hypertrophy.

B Artery with extensive intima fibrosis, subtotal luminal occlusion and recanalisation.

C, D Plexiform lesions (EvG-staining) adjacent to a feeding artery with intimal fibrosis, media hypertrophy (C) and collection of convoluted, dilated thin-walled vessel segments simulating a haemangioma (D).

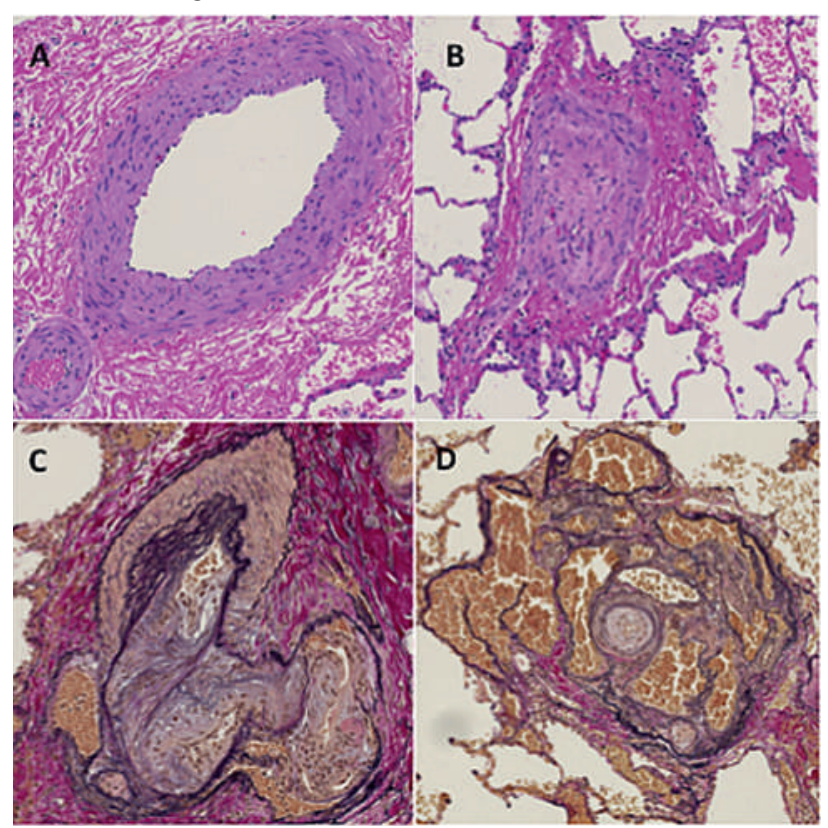

\section{Vascular remodelling}

Vascular remodelling is arguably the most important pathogenetic event in the development of pulmonary arterial hypertension. In contrast to vasoconstriction and microthrombosis which can be treated successfully, vascular remodelling of small pulmonary arteries is recognised as the main cause of the chronicity and progression of pulmonary hypertension and explains the refractoriness of the disease to current therapeutic regimens. This remodelling is characterised by an excessive proliferation of vascular smooth muscle cells and the formation of a neointimal layer, which result in increased thickness of the pulmonary arterial vessel wall and occlusion of the vascular lumen $[49,50]$. With the exception of plexiform lesions, which are focal proliferations of endothelial channels lined by myofibroblasts [51] and a characteristic feature of group 1 pulmonary arterial hypertension, the pattern of vascular remodelling is indistinguishable between the different aetiologies of elevated pulmonary pressure [52]. A characteristic example of vascular remodelling in pulmonary hypertension is provided in figure 5 .

Despite many advances, the pathogenesis of the vascular remodelling is still a matter of debate. It has been demonstrated that a complex network of different factors, including growth factors, neurohumoral transmitters, infections, inflammatory cells, cytokines, chemokines and voltage-gated potassium channels, contribute to the remodelling process. A major role in triggering vascular remodelling has been attributed to the bone morphogenetic protein receptor type II (BMPR2). The BMPR2 is a member of a family of growth factor receptors (transforming growth factor beta receptors) and located at the surface of endothelial and vascular smooth muscle cells. Mutations in the BMPR2 result in increased cell survival and proliferation, and have been identified as causative factors in the development of hereditary pulmonary arterial hypertension. The fact that BMPR2 mutations can be found in up to $70 \%$ of families with pulmonary hypertension and in up to one third of patients with idiopathic pulmonary arterial hypertension indicate that additional factors are responsible for the development and progression of pulmonary hypertension. In recent years, it has become clear that in many nongenetic forms of pulmonary hypertension - such as congenital heart disease [53, 54], HIV-infection [55], left heart disease [54] and chronic hypoxia including the major experimental models of the disease $[56,57]$ - the BMPR2 is downregulated and its signalling pathways are dysfunctional. This downregulation might be due to the action of microRNAs (i.e., small noncoding RNA fragments) that bind to the mRNA of the BMPR2 and inhibit its translation [58]. The use of BMPR2 transfection in case of genetic mutations or the application of antagomiRs that inhibit microRNAs specifically in nongenetic forms of the disease have been shown to prevent 
or treat vascular remodelling and improve haemodynamics in experimental models of the disease [59-62]. Whether such an approach for a "reverse remodelling" is feasible and successful in human disease remains to be elucidated.

\section{Acknowledgement}

We would like to thank PD Dr Matthias Greutmann (Head Congenital Heart Disease, University Hospital Zurich) for helpful comments on GUCH patients with pulmonary arterial hypertension.

\section{References}

1 Wilkins LW, West JB. Respiratory Physiology. 2012.

2 Bae S, Saggar R, Bolster MB, Chung L, Csuka ME, Derk C, et al. Baseline characteristics and follow-up in patients with normal haemodynamics versus borderline mean pulmonary arterial pressure in systemic sclerosis: results from the PHAROS registry. Ann Rheum Dis. 2012; 71(8):1335-42.

3 Hoeper MM, Bogaard HJ, Condliffe R, Frantz R, Khanna D, Kurzyna $\mathrm{M}$, et al. Definitions and diagnosis of pulmonary hypertension. J Am Coll Cardiol. 2013;62(25 Suppl):D42-50.

4 Lam CSP, Borlaug BA, Kane GC, Enders FT, Rodeheffer RJ, Redfield MM. Age-associated increases in pulmonary artery systolic pressure in the general population. Circulation. Lippincott Williams \& Wilkins; 2009;119(20):2663-70.

5 McQuillan BM, Picard MH, Leavitt M, Weyman AE. Clinical Correlates and Reference Intervals for Pulmonary Artery Systolic Pressure Among Echocardiographically Normal Subjects. Circulation. 2001;104(23): 2797-802.

6 Janda S, Shahidi N, Gin K, Swiston J. Diagnostic accuracy of echocardiography for pulmonary hypertension: a systematic review and meta-analysis. Heart. 2011;97(8):612-22.

7 Knowlton FP, Starling EH. The influence of variations in temperature and blood-pressure on the performance of the isolated mammalian heart. J Physiol. 1912;44(3):206-19.

8 Halpern SD. Misclassification of Pulmonary Hypertension Due to Reliance on Pulmonary Capillary Wedge Pressure Rather Than Left Ventricular End-Diastolic Pressure. Chest. 2009;136(1):37.

9 Vachiéry J-L, Adir Y, Barberà JA, Champion H, Coghlan JG, Cottin V, et al. Pulmonary hypertension due to left heart diseases. J Am Coll Cardiol. 2013;62(25 Suppl):D100-8.

10 Sitbon O. Long-Term Response to Calcium Channel Blockers in Idiopathic Pulmonary Arterial Hypertension. Circulation. 2005;111(23): 3105-11.

11 Robbins IM, Hemnes AR, Pugh ME, Brittain E, Zhao DX, Piana RN, et al. High Prevalence of Occult Pulmonary Venous Hypertension Revealed by Fluid Challenge in Pulmonary Hypertension. Circulation: Heart Failure. 2013 Dec 2.

12 Authors/Task Force Members, Galie N, Hoeper MM, Humbert M, Torbicki A, Vachiery JL, et al. Guidelines for the diagnosis and treatment of pulmonary hypertension: The Task Force for the Diagnosis and Treatment of Pulmonary Hypertension of the European Society of Cardiology (ESC) and the European Respiratory Society (ERS), endorsed by the International Society of Heart and Lung Transplantation (ISHLT). Eur Heart J. 2009;30(20):2493-537.

13 Hansdottir S, Groskreutz DJ, Gehlbach BK. WHO's in Second? Chest. 2013;144(2):638.

14 Arrigo M, Huber LC. Passive Pulmonary Hypertension. Chest. 2014;145(2):413.

15 Ling Y, Johnson MK, Kiely DG, Condliffe R, Elliot CA, Gibbs JSR, et al. Changing Demographics, Epidemiology, and Survival of Incident Pulmonary Arterial Hypertension. Am J Respir Crit Care Med. 2012; 186(8):790-6.

16 Humbert M, Sitbon O, Chaouat A, Bertocchi M, Habib G, Gressin V, et al. Pulmonary Arterial Hypertension in France. Am J Respir Crit Care Med. 2006;173(9):1023-30.

17 Simonneau G, Gatzoulis MA, Adatia I, Celermajer D, Denton C, Ghofrani A, et al. Updated clinical classification of pulmonary hypertension. J Am Coll Cardiol. 2013;62(25 Suppl):D34-41.
18 International PPH Consortium, Lane KB, Machado RD, Pauciulo MW, Thomson JR, Phillips JA, et al. Heterozygous germline mutations in BMPR2, encoding a TGF-beta receptor, cause familial primary pulmonary hypertension. Nat Genet. 2000;26(1):81-4.

19 Hervier B, Meyer A, Dieval C, Uzunhan Y, Devilliers H, Launay D, et al. Pulmonary hypertension in antisynthetase syndrome: prevalence, aetiology and survival. Eur Respir J. 2013;42(5):1271-82.

20 Mukerjee D, St George D, Coleiro B, Knight C, Denton CP, Davar J, et al. Prevalence and outcome in systemic sclerosis associated pulmonary arterial hypertension: application of a registry approach. Ann Rheum Dis. 2003;62(11):1088-93.

21 Coghlan G. Does left heart disease cause most systemic sclerosis associated pulmonary hypertension? Eur Respir J. 2013;42(4):888-90.

22 Fox BD, Shimony A, Langleben D, Hirsch A, Rudski L, Schlesinger R, et al. High prevalence of occult left heart disease in scleroderma-pulmonary hypertension. Eur Respir J. 2013;42(4):1083-91.

23 WOOD P. The Eisenmenger syndrome or pulmonary hypertension with reversed central shunt. I. Br Med J. 1958;2(5098):701-9.

24 Marelli AJ, Mackie AS, Ionescu-Ittu R, Rahme E, Pilote L. Congenital Heart Disease in the General Population: Changing Prevalence and Age Distribution. Circulation. 2006;115(2):163-72.

25 Beghetti M. Fontan and the pulmonary circulation: a potential role for new pulmonary hypertension therapies. Heart. BMJ Publishing Group Ltd and British Cardiovascular Society; 2010;96(12):911-6.

26 Hervé P, Lebrec D, Brenot F, Simonneau G, Humbert M, Sitbon O, et al. Pulmonary vascular disorders in portal hypertension. Eur Respir J. 1998;11(5):1153-66.

27 Pellicelli AM, Barbaro G, Puoti C, Guarascio P, Lusi EA, Bellis L, et al. Plasma Cytokines and Portopulmonary Hypertension in Patients With Cirrhosis Waiting for Orthotopic Liver Transplantation. Angiology. 2010;61(8):802-6.

28 Kawut SM, Krowka MJ, Trotter JF, Roberts KE, Benza RL, Badesch $\mathrm{DB}$, et al. Clinical risk factors for portopulmonary hypertension. Hepatology. 2008;48(1):196-203.

29 Savale L, Chaumais MC, Cottin V, Bergot E, Frachon I, Prevot G, et al. Pulmonary hypertension associated with benfluorex exposure. European Respiratory Journal. European Respiratory Society; 2012;40(5): 1164-72.

30 Montani D, Bergot E, Gunther S, Savale L, Bergeron A, Bourdin A, et al. Pulmonary Arterial Hypertension in Patients Treated by Dasatinib. Circulation. 2012;125(17):2128-37.

31 Ghofrani HA, Seeger W, Grimminger F. Imatinib for the treatment of pulmonary arterial hypertension. N Engl J Med. 2005;353(13):1412-3.

32 Speich R, Treder U, Domenighetti G, Huber LC, Ulrich S. Weaning from intravenous prostanoids and normalization of hemodynamics by longterm imatinib therapy in severe idiopathic pulmonary arterial hypertension. Int J Clin Pharm. 2013 Nov 28.

33 Hoeper MM, Barst RJ, Bourge RC, Feldman J, Frost AE, Galie N, et al. Imatinib Mesylate as Add-on Therapy for Pulmonary Arterial Hypertension: Results of the Randomized IMPRES Study. Circulation. 2013;127(10):1128-38.

34 Schiess R. Tobacco Smoke: A Risk Factor for Pulmonary Arterial Hypertension? Chest. 2010;138(5):1086.

35 Santos S, Peinado VI, Ramirez J, Melgosa T, Roca J, Rodriguez-Roisin $\mathrm{R}$, et al. Characterization of pulmonary vascular remodelling in smokers and patients with mild COPD. Eur Respir J. 2002;19(4):632-8.

36 Trip P, Nossent EJ, de Man FS, van den Berk IAH, Boonstra A, Groepenhoff $\mathrm{H}$, et al. Severely reduced diffusion capacity in idiopathic pulmonary arterial hypertension: patient characteristics and treatment responses. Eur Respir J. 2013;42(6):1575-85.

37 Speich R. Primary pulmonary hypertension in HIV infection. Chest. 1991;100(5):1268.

38 Cool CD, Rai PR, Yeager ME, Hernandez-Saavedra D, Serls AE, Bull TM, et al. Expression of human herpesvirus 8 in primary pulmonary hypertension. N Engl J Med. 2003;349(12):1113-22.

39 Zuber J-P, Calmy A, Evison JM, Hasse B, Schiffer V, Wagels T, et al. Pulmonary arterial hypertension related to HIV infection: improved hemodynamics and survival associated with antiretroviral therapy. Clin Infect Dis. Oxford University Press; 2004;38(8):1178-85.

40 Sommer N, Dietrich A, Schermuly RT, Ghofrani HA, Gudermann T, Schulz R, et al. Regulation of hypoxic pulmonary vasoconstriction: basic mechanisms. Eur Respir J. 2008;32(6):1639-51.

41 Rubens C, Ewert R, Halank M, Wensel R, Orzechowski HD, Schultheiss HP, et al. Big endothelin-1 and endothelin-1 plasma levels are correlated with the severity of primary pulmonary hypertension. Chest. 2001;120(5):1562-9. 
42 Giaid A, Saleh D. Reduced expression of endothelial nitric oxide synthase in the lungs of patients with pulmonary hypertension. N Engl $\mathrm{J}$ Med. 1995;333(4):214-21.

43 Tuder RM, Cool CD, Geraci MW, Wang J, Abman SH, Wright L, et al. Prostacyclin synthase expression is decreased in lungs from patients with severe pulmonary hypertension. Am J Respir Crit Care Med. 1999; 159(6):1925-32.

44 Arrigo M, Huber LC. Eponyms in cardiopulmonary reflexes. Am J Cardiol. Elsevier; 2013;112(3):449-53.

45 Wagenvoort CA, Mulder PG. Thrombotic lesions in primary plexogenic arteriopathy. Similar pathogenesis or complication? Chest. 1993;103(3): 844-9.

46 Welsh CH, Hassell KL, Badesch DB, Kressin DC, Marlar RA. Coagulation and fibrinolytic profiles in patients with severe pulmonary hypertension. Chest. 1996;110(3):710-7.

47 Hoeper MM, Sosada M, Fabel H. Plasma coagulation profiles in patients with severe primary pulmonary hypertension. Eur Respir J. 1998;12(6): 1446-9.

48 Johnson SR, Granton JT, Tomlinson GA, Grosbein HA, Hawker GA, Feldman BM. Effect of warfarin on survival in scleroderma-associated pulmonary arterial hypertension (SSc-PAH) and idiopathic PAH. Belief elicitation for Bayesian priors. J Rheumatol. The Journal of Rheumatology; 2011;38(3):462-9.

49 Dorfmuller P, Humbert M. Progress in pulmonary arterial hypertension pathology: relighting a torch inside the tunnel. Am J Respir Crit Care Med. 2012;186(3):210-2.

50 Guignabert C, Dorfmuller P. Pathology and Pathobiology of Pulmonary Hypertension. Semin Respir Crit Care Med. 2013;34(05):551-9.

51 Pietra GG, Capron F, Stewart S, Leone O, Humbert M, Robbins IM, et al. Pathologic assessment of vasculopathies in pulmonary hypertension. J Am Coll Cardiol. 2004;43(12):S25-S32.

52 Dorfmüller P, Humbert M, Capron F. Update on the pathomorphological assessment of vasculopathies in pulmonary arterial hypertension. Pathologe. 2006;27(2):140-6.

53 Atkinson C. Primary Pulmonary Hypertension Is Associated With Reduced Pulmonary Vascular Expression of Type II Bone Morphogenetic Protein Receptor. Circulation. 2002;105(14):1672-8.

$54 \mathrm{MD} \mathrm{HI}, \mathrm{MD} \mathrm{SK}, \mathrm{PhD}$ KTM, PhD KOM. Attenuation of bone morphogenetic protein receptor type 2 expression in the pulmonary arteries of patients with failed Fontan circulation. The Journal of Thoracic and Cardiovascular Surgery. The American Association for Thoracic Surgery; 2012;143(4):e24-6.

55 Dalvi P, O'Brien-Ladner A, Dhillon NK. Downregulation of Bone Morphogenetic Protein Receptor Axis During HIV-1 and Cocaine-Mediated Pulmonary Smooth Muscle Hyperplasia: Implications for HIV-Related Pulmonary Arterial Hypertension. Arterioscler Thromb Vasc Biol. 2013;33(11):2585-95.

56 Takahashi H. Downregulation of type II bone morphogenetic protein receptor in hypoxic pulmonary hypertension. AJP: Lung Cellular and Molecular Physiology. 2005;290(3):L450-8.
57 Morty RE, Nejman B, Kwapiszewska G, Hecker M, Zakrzewicz A, Kouri FM, et al. Dysregulated Bone Morphogenetic Protein Signaling in Monocrotaline-Induced Pulmonary Arterial Hypertension. Arterioscler Thromb Vasc Biol. 2007;27(5):1072-8.

58 Brock M, Trenkmann M, Gay RE, Michel BA, Gay S, Fischler M, et al. Interleukin-6 Modulates the Expression of the Bone Morphogenic Protein Receptor Type II Through a Novel STAT3-microRNA Cluster 17/92 Pathway. Circ Res. 2009;104(10):1184-91.

59 Reynolds AM, Xia W, Holmes MD, Hodge SJ, Danilov S, Curiel DT, et al. Bone morphogenetic protein type 2 receptor gene therapy attenuates hypoxic pulmonary hypertension. AJP: Lung Cellular and Molecular Physiology. 2007;292(5):L1182-92.

60 Reynolds AM, Holmes MD, Danilov SM, Reynolds PN. Targeted gene delivery of BMPR2 attenuates pulmonary hypertension. Eur Respir J. 2012;39(2):329-43.

61 Pullamsetti SS, Doebele C, Fischer A, Savai R, Kojonazarov B, Dahal BK, et al. Inhibition of MicroRNA-17 Improves Lung and Heart Function in Experimental Pulmonary Hypertension. Am J Respir Crit Care Med. 2012;185(4):409-19.

62 Brock M, Samillan VJ, Trenkmann M, Schwarzwald C, Ulrich S, Gay $\mathrm{RE}$, et al. AntagomiR directed against miR-20a restores functional BMPR2 signalling and prevents vascular remodelling in hypoxia-induced pulmonary hypertension. Eur Heart J. 2012 Mar 26.

63 Swan HJ, Ganz W, Forrester J, Marcus H, Diamond G, Chonette D. Catheterization of the heart in man with use of a flow-directed balloon-tipped catheter. N Engl J Med. 1970;283(9):447-51.

64 Bonderman D, Wexberg P, Martischnig AM, Heinzl H, Lang MB, Sadushi $\mathrm{R}$, et al. A noninvasive algorithm to exclude pre-capillary pulmonary hypertension. Eur Respir J. 2011;37(5):1096-103.

65 Aduen JF, Castello R, Lozano MM, Hepler GN, Keller CA, Alvarez F, et al. An Alternative Echocardiographic Method to Estimate Mean Pulmonary Artery Pressure: Diagnostic and Clinical Implications. Journal of the American Society of Echocardiography. Elsevier; 2009;22(7): 814-9.

66 Chemla D. New Formula for Predicting Mean Pulmonary Artery Pressure Using Systolic Pulmonary Artery Pressure. Chest. 2004;126(4): 1313-7.

67 Rajaram S, Swift AJ, Telfer A, Hurdman J, Marshall H, Lorenz E, et al. $3 \mathrm{D}$ contrast-enhanced lung perfusion MRI is an effective screening tool for chronic thromboembolic pulmonary hypertension: results from the ASPIRE Registry. Thorax. BMJ Publishing Group Ltd and British Thoracic Society; 2013;68(7):677-8.

68 Paulus WJ, Tschope C, Sanderson JE, Rusconi C, Flachskampf FA, Rademakers FE, et al. How to diagnose diastolic heart failure: a consensus statement on the diagnosis of heart failure with normal left ventricular ejection fraction by the Heart Failure and Echocardiography Associations of the European Society of Cardiology. Eur Heart J. 2007; 28(20):2539-50. 